\title{
Pantanal ameaçado: a construção de represas e a insignificância da energia hídrica produzida ${ }^{1}$
}

\author{
Pantanal under threat: the construction of dams and the insignificance of the \\ produced water energy
}

\section{Pantanal amenazado: la construcción de represas y la insignificancia de la energía hidroeléctrica producida}

\author{
Silvia Cristina Santana Zanatta \\ Josemar de Campos Maciel $^{2}$
}

Recebido em 06/11/2019; revisado e aprovado em 11/03/2020; aceito em 17/07/2020

DOI: http://dx.doi.org/10.20435/inter.v22i2.2811

\begin{abstract}
Resumo: Há problemas de grande escala que se manifestam em esferas e situações localizadas. No texto que segue, retrata-se um desses casos, talvez o mais emblemático da atualidade: a Bacia do Alto Rio Paraguai (BAP). Neste presente artigo, será apresentada sua dinâmica e um dos principais problemas relativos à sua sustentabilidade, a barragem de rios para produção de energia. A pesquisa foi construída a partir de bases de dados oficiais, em estreita comunicação com populações locais e referenciamento geocartográfico, e se volta 1) para a desconstrução da falácia da narrativa construída que justifica a exploração do território; 2) para provar que a energia produzida por estes empreendimentos em operação é absolutamente insignificante à manutenção da matriz de produção energética brasileira. Pretende-se, assim, contribuir com dados para que a sociedade civil e especialistas possam instruir-se acerca dos termos de um debate urgente. A pesquisa foi realizada com base na hipótese de que, no processo ainda em curso de ocupação da BAP como território produtor de energia hídrica, a tendência é de que as Usinas Hidrelétricas não contribuam de forma significativa para o painel nacional de produção de energia e, muito menos, para o desenvolvimento local e sustentável dos municípios onde são instaladas.
\end{abstract}

Palavras-chave: represas; populações vulneráveis; Bacia do Alto Rio Paraguai; energia.

Abstract: There are large-scale problems that manifest themselves in localized spheres and situations. The following text presents one of these cases, perhaps the most emblematic today: the Upper Paraguay River Basin (BAP). One presents its dynamics and one of the main problems related to its sustainability, that is, the importance of the dams for the production of energy. The sources are official databases in close communication with local populations and geocartographic referencing. It turns to 1 ) deconstruct the fallacy of the constructed narrative that justifies the exploration of the territory; 2) prove that the energy produced by these power plants in operation is absolutely insignificant for the maintenance of the Brazilian energy production matrix. Thus, the work rends data available to the civil society and experts, so that they can inform themselves about some terms of an urgent debate. The study was carried out based on the hypothesis that, in the process that is still underway in the occupation of the UPB as a hydropower producing territory, the tendency is that the Hydroelectric Plants do not contribute significantly to the national grid for energy production and, at least for the local and sustainable development of the municipalities where they are located.

Keywords: dams; vulnerable populations; the Upper Paraguay River Basin; energy.

Resumen: Hay problemas de gran escala que se manifiestan en esferas y situaciones localizadas. En el texto, se presenta aquello que probablemente es el caso más emblemático de la actualidad, por lo que toca la relación entre energía y desarrollo: la Cuenca del Alto Rio Paraguay (BAP). Se presentan su dinámica y uno de los principales problemas con su sustentabilidad, el embalse del río para generación de energía. Las fuentes son todas construidas a partir de bases y datos oficiales, con estrecha comunicación de las poblaciones locales y referencias cartográficas, y se vuelven: (1) para deconstruir la falacia de la narrativa que justifica la exploración del territorio; (2) para demostrar que la energía producida por esas empresas en operación es absolutamente insignificante para mantenimiento de la matriz energética brasileña. Así, el trabajo contribuye

\footnotetext{
${ }^{1}$ Este artigo é produto da Tese de Doutorado intitulada "Saudade do cheiro do rio- Empreendimentos hidrelétricos na BAP e os caminhos de resistência da vocalidade ribeirinha", do Programa de Pós-Graduação de Mestrado e Doutorado em Desenvolvimento Local da Universidade Católica Dom Bosco (UCDB). O trabalho teve o apoio financeiro da CAPES e o apoio institucional da Organização Não Governamental Ecoa - Ecologia e Ação.

2 Universidade Católica Dom Bosco (UCDB), Campo Grande, Mato Grosso do Sul, Brasil.
} 
con datos para que la sociedad civil y los peritos puedan conocer algunos termos de una discusión urgente. La investigación se realizó con base en la hipótesis de que, en el proceso que aún se encuentra en marcha para ocupar la CAP como territorio productor de energía hidroeléctrica, la tendencia es que las Centrales Hidroeléctricas no aporten de manera significativa al panel nacional de producción de energía y, mucho menos para el desarrollo local y sostenible de los municipios donde se instalan.

Palabras clave: represas; poblaciones vulnerables; Cuenca del Alto Río Paraguay; energía.

\section{INTRODUÇÃO}

O desenvolvimento é um processo, não um terminus ad quem. Historicamente, esse processo é liderado por três grandes mecanismos possíveis. Se iniciado pelo estado, sobretudo a partir dos estados modernos, ele se configura como uma disputa pelo controle de territórios. Se iniciado a partir de atores privados, o movimento é de individualização, levando à construção de mercados mais estruturados. O terceiro mecanismo é rizomático. Ele procede de iniciativas caóticas, fundadas nas dinâmicas socioterritoriais, e ganha escala de forma reticular a partir dos outros dois. Aqui é sustentada a ideia de que o terceiro mecanismo está sendo fragilizado pelo movimento de sequestro das dinâmicas institucionais, por interesses prioritariamente econômicos.

No caso deste trabalho, tem-se o cenário dos rios da Bacia do Alto Rio Paraguai, representando o ambiente; empresas de geração de energia transnacionais com capital especulativo associado, representando os atores privados de grande escala; e populações ribeirinhas, representando o movimento rizomático dos territórios. Os estados têm pressa. Os investidores precisam maximizar o seu lucro para sustentar-se no palco das competições. Os ribeirinhos, que são radicados literalmente na porção do ambiente que está em disputa, aparecem como figurantes indesejados em uma competição de grandes proporções.

Entendemos que um novo movimento é necessário. Um movimento que traga como protagonistas estes grupos sociais em situação de vulnerabilidade e que, a partir deles, seja dada a formação de um modelo de relação com o ambiente que não seja apressadamente destrutivo. Acreditamos ser necessário pensar o desenvolvimento a partir de limites. É no reconhecimento dos limites - dos ecossistemas, da fragilidade do humano, dos modos de vida - que se encontram as maiores possibilidades para ampliação do que venha a ser um modelo de desenvolvimento respeitoso. Sendo assim, o texto que segue busca apontar limites que vêm sendo excedidos em nome de um modelo de desenvolvimento que não dá espaço para escuta sistêmica de fontes realmente detentoras do conhecimento sobre o território.

O primeiro esforço do trabalho está na apresentação da sensível dinâmica do território que sofre a pressão do estado e dos atores privados, a BAP. A seção que segue já apresenta as populações detentoras deste território e concede a elas o papel da resistência diante das violências as quais sempre foram submetidas. Depois, tratamos de apresentar o perigo envolvendo o plano de exploração dos recursos hídricos da Bacia, como se deu a estratégia macro de produção energética brasileira e qual o papel que a BAP desempenha dentro deste cenário desenvolvimentista.

\section{TERRITÓRIO DAS ÁGUAS}

A Bacia Hidrográfica do Alto Rio Paraguai abarca duas grandes regiões física e ecologicamente bem demarcadas: a Planície, sua parte mais baixa e conhecida como Pantanal, e 
o Planalto que o circunda, mais elevado. As duas regiões compõem "universos" muito distintos, mas interdependentes nos marcos da grande unidade ambiental "Bacia Hidrográfica" e outros elementos, como a vegetação. Ter presentes as características físicas e biológicas da BAP é importante, porque, a o fim, as construções econômicas e sociais observadas ao longo da história e presentes hoje estão diretamente relacionadas com elas.

\subsection{A Planície}

Chamada também de Pantanal, é uma região baixa onde os rios inundam e alimentam um intrincado sistema de drenagem que inclui extensos lagos, cursos d'água divergentes e áreas de escoamento e inundação sazonal. A região do Pantanal apresenta cotas entre 80 metros e 150 metros de altura, e foi formada pelo rebaixamento de uma grande região, simultaneamente ao soerguimento da Cordilheira dos Andes (SILVA, 1986).

A medida da importância desta região está no fato de ser reconhecida como Patrimônio Nacional pela Constituição Federal e parte dela ser considerada Reserva da Biosfera e Patrimônio Natural da Humanidade pela Organização das Nações Unidas para a Educação, a Ciência e a Cultura (UNESCO), além de abrigar três Sítios Ramsar, ou seja, zonas úmidas que se beneficiam de prioridade no acesso à cooperação técnica internacional e apoio financeiro para promover projetos que visem a sua proteção e à utilização sustentável dos seus recursos naturais, favorecendo a implantação, em tais áreas, de um modelo de desenvolvimento que proporcione qualidade de vida aos seus habitantes.

\subsection{O Planalto}

O Planalto está quase totalmente em território brasileiro e tem cerca de 200.000 km². Pode atingir entre 500 metros e 1.400 metros de altitude nas regiões norte e leste da Bacia, onde se localizam as nascentes dos rios da BAP. Conforme aponta o estudo de monitoramento das alterações da cobertura vegetal e uso do solo na Bacia do Alto Rio Paraguai (2009), além da fragilidade natural proporcionada pelas condições do relevo e pela natureza dos solos, o Planalto é a porção da Bacia que mais sofreu, ao longo dos últimos anos, com intervenções humanas.

\subsection{A Bacia na América do Sul}

A Bacia do Alto Rio Paraguai distribui-se pela Bolívia, pelo Paraguai e pelo Brasil (Figura 1), com uma área total de $624.320 \mathrm{~km}^{2}$ - um território pouco menor que a França. No Brasil, estão $62 \%\left(361.666 \mathrm{~km}^{2}\right)$ da Bacia, outros 20\% encontram-se na Bolívia, e 18\%, no Paraguai. 
Figura 1 - Localização da Bacia do Alto Rio Paraguai na América do Sul

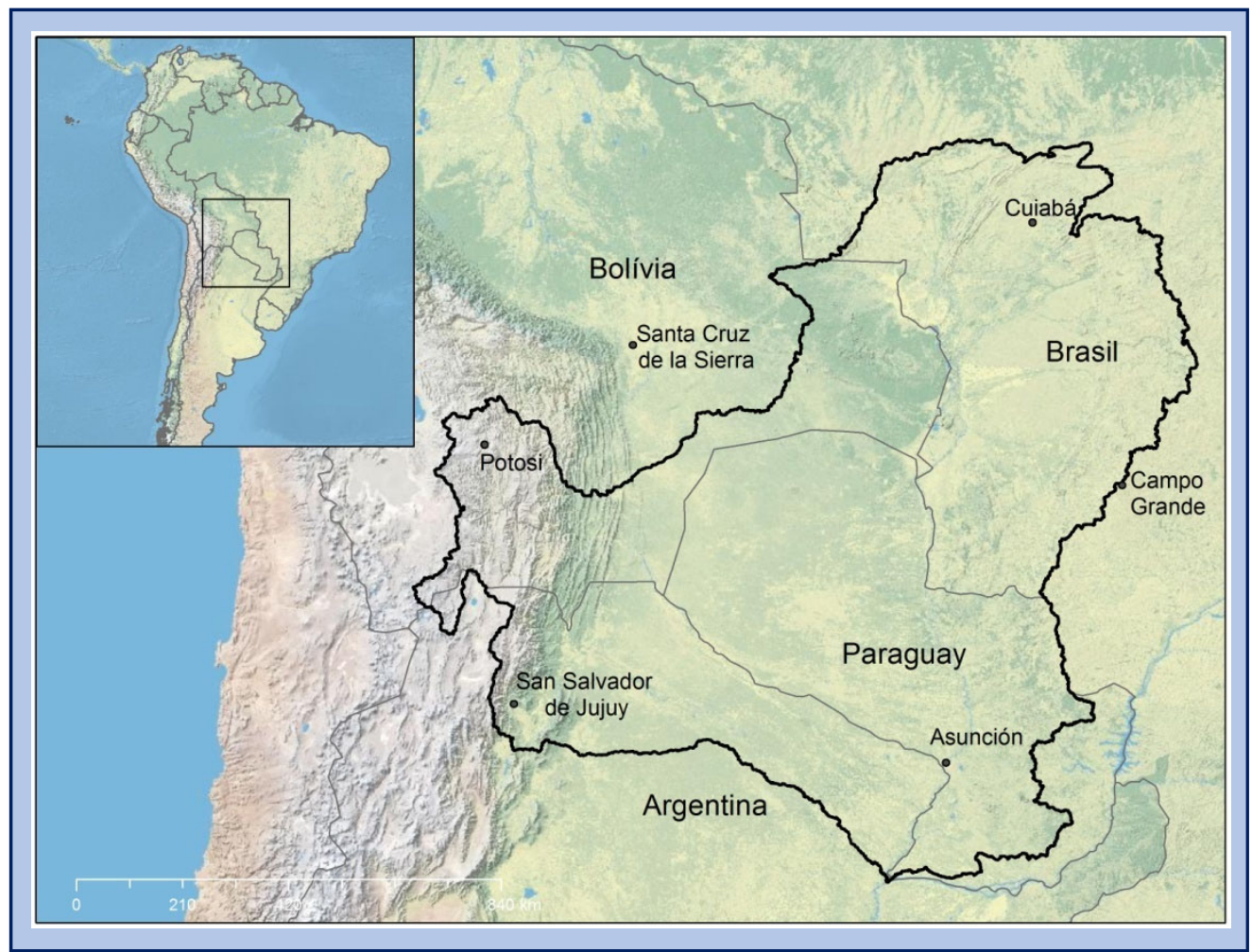

Fonte: The Nature Conservancy e WWF-Brasil (TNC; WWF, 2011).

A área de Planície/Pantanal ocupa 190.000 km² nos três países, sendo que, em território brasileiro, são $140.000 \mathrm{~km}^{2}$ ou quase $74 \%$ do total, distribuídos pelos estados de Mato Grosso e Mato Grosso do Sul. Situado no centro da América do Sul, o Pantanal é parte do Sistema Paraguai-Paraná de Áreas Úmidas, localizado no Vale Central da América do Sul/Depressão Subandina. Além do Pantanal, na parte alta da Bacia do Alto Rio Paraguai, este sistema inclui as áreas úmidas do Rio Paraguai médio e inferior e o vale aluvial do Paraná médio e inferior, até a desembocadura do Rio da Prata. Mais de 20 milhões de pessoas o habitam. São comunidades indígenas, tradicionais e populações de áreas urbanas e rurais.

Um registro importante é que a Bacia do Alto Rio Paraguai, juntamente das Bacias do Paraná e Uruguai, forma a grande Bacia do Rio da Prata, distribuída por Uruguai, Argentina, Paraguai, Bolívia e Brasil. Neste território de $3.200 .000 \mathrm{~km}^{2}$, a magnitude dos números que descrevem esse sistema hidrográfico evidencia sua importância estratégica. Nele, são gerados $70 \%$ do Produto Interno Bruto (PIB) dos cinco países que o integram e vive cerca de 50\% da população dessas nações (AGÊNCIA NACIONAL DE ÁGUAS [ANA], 2001).

\section{UM TERRITÓRIO AMEAÇADO - O BARRAMENTO DOS RIOS}

Apesar da importância deste território e da existência de iniciativas de se discutir sobre a BAP de forma pautada em planos e programas, como por meio do Estudo de Desenvolvimento Integrado da Bacia do Alto Paraguai (EDIBAP)/Brasil (1979) e do Plano de Conservação da Bacia do Alto Paraguai (Pantanal) (BRASIL, 1997), por exemplo, ambos recomendando o uso dos recursos naturais de forma mais racional, visando à sustentabilidade do território, pouco tem 
sido feito efetivamente para adoção de políticas que se consolidem e protejam a região das ações predatórias. Exemplo disso é o movimento que se dá a partir do início dos anos 2000, com a elaboração de inúmeros projetos de barramentos de rios no Planalto, os quais, como se sabe, drenam para o Pantanal.

Este movimento se dá, necessariamente, a partir da narrativa de que, com a exploração da hidroeletricidade e a implantação de Usinas Hidrelétricas (UHEs), Centrais Geradoras Hidrelétricas (CGHs) e as Pequenas Centrais Hidrelétricas ( $\mathrm{PCHs}$ ), serão produzidas fontes limpas de geração de energia, particularmente com esta última. Este é um discurso que, para Bernam (2004), deve ser analisado com profundidade, pois não existe energia limpa; em maior ou menor grau, todas as fontes de energia provocam danos ao ambiente.

Outro mecanismo que se fez valer pelo estado neste período, para fortalecer a ideia de que a Bacia era importante dentro do quadro de produção energética do Brasil, foi a chamada eletroestratégia, uma analogia feita por Albuquerque (2013) ao conceito de agroestratégia de Almeida (2010), em que o setor energético, assim como o setor do agronegócio, utiliza inúmeras táticas para benefício próprio. Uma das narrativas que demonstra bem esta equidade é o discurso de "crise na produção de alimentos" para o agronegócio e a "crise energética" para o setor energético. A terminologia "apagão" foi bastante utilizada neste período, para justificar os inúmeros empreendimentos hidrelétricos implantados na Bacia e proporcionar facilidades, como as descritas no Programa de Incentivo às Fontes Alternativas de Energia Elétrica (PROINFA), instituída por meio do Decreto n. 5.025, de 2004, em que se oferece um pacote de benefícios para os empreendedores, como o financiamento pelo Banco Nacional de Desenvolvimento Social e Econômico (BNDES) de até $80 \%$ do empreendimento, a garantia da compra de energia assegurada pela Eletrobras, a isenção do pagamento de Uso de Bem Público (UBP) e a isenção de compensação aos estados e municípios pelo uso de recursos hídricos, entre outras facilidades. Tudo, sempre, em nome de se evitar um grande colapso energético.

\section{A QUESTÃO ENERGÉTICA BRASILEIRA E O PAPEL DA BAP}

A maior parte da energia elétrica produzida no Brasil tem procedência de empreendimentos hidrelétricos, que respondem a 63,89\% de toda a capacidade instalada do país, hoje calculada em 164,03 mil quilowatts (kW). De acordo com o Banco de Informações de Geração, da Agência Nacional de Energia Elétrica (ANEEL), os 1.341 empreendimentos de geração hidráulica instalados no território nacional têm capacidade de gerar 108,46 mil kW. A dependência do país diante dessa matriz geradora de energia é nítida, apesar do avanço de outras fontes nos últimos anos, como indicado a seguir, no Quadro 1 e na Figura 2. 
Quadro 1 - Fontes energéticas em operação utilizadas no Brasil

\begin{tabular}{|l|c|c|c|c|}
\hline \multicolumn{5}{|c|}{ Fontes utilizadas no Brasil - Fase: Operação } \\
\hline \multicolumn{1}{|c|}{ Origem } & Quantidade & Potência Outorgada (kW) & Potência Fiscalizada (kW) & $\%$ \\
\hline Hídrica & 1.341 & 108.462 .348 & 104.588 .321 & 63,98 \\
\hline Fóssil & 2.440 & 27.087 .479 & 25.614 .887 & 15,98 \\
\hline Eólica & 611 & 15.024 .289 & 14.978 .393 & 8,86 \\
\hline Biomassa & 566 & 14.872 .209 & 14.786 .872 & 8,77 \\
\hline Solar & 2.469 & 2.076 .252 & 2.074 .002 & 1,22 \\
\hline Nuclear & 02 & 1.990 .000 & 1.990 .000 & 1,17 \\
\hline Undi-Elétrica & 01 & 50 & 50 & 0,02 \\
\hline Total & 7.430 & 169.512 .628 & 164.032 .526 & 100 \\
\hline
\end{tabular}

Fonte: Sistema de Informação de Geração da ANEEL - SIGA (ANEEL, 2019).

Figura 2 - Fontes energéticas em operação utilizadas no Brasil

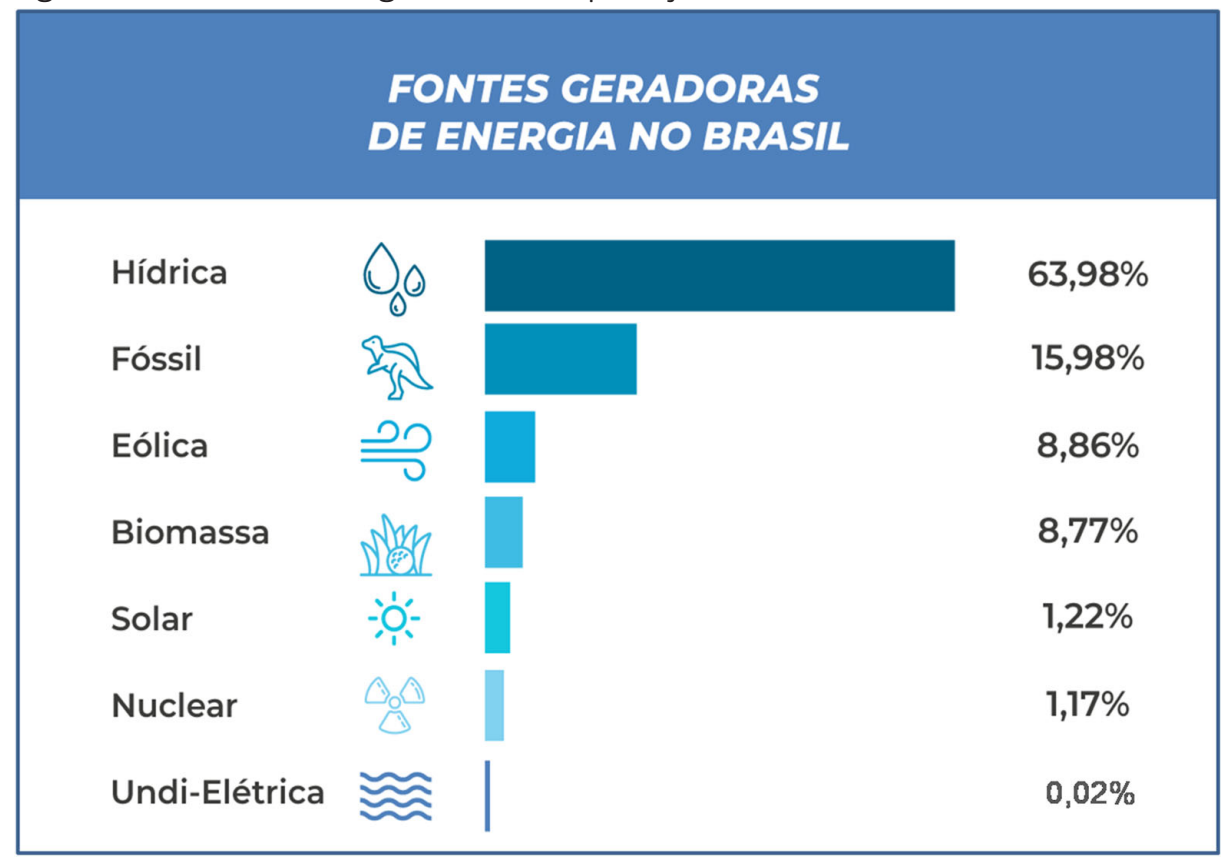

Fonte: Figura elaborada a partir dos dados do Banco de Informações de Geração (BIG) - ANEEL.

De acordo com o Sistema de Informações do Potencial Hidrelétrico Brasileiro (SIPOT), desenvolvido pela Eletrobras, com o objetivo de armazenar e processar informações sobre estudos e projetos de usinas hidrelétricas, o potencial hidrelétrico brasileiro, tecnicamente explorável, é da ordem de 260 GW. O potencial técnico de aproveitamento da energia hidráulica do Brasil está entre os cinco maiores do mundo, pois o país tem $12 \%$ da água doce superficial do planeta. Dados que continuam a colaborar para o fortalecimento da narrativa de que o Brasil tem o "dever" de barrar seus rios para a produção de mais energia.

Deste potencial hidrelétrico de 260 GW, 42,2\% estão localizados na Bacia Hidrográfica do Amazonas. Já a Bacia do Alto Rio Paraguai é responsável por somente 1,2\% deste montante. Um percentual baixíssimo de oferta de produção de energia ante os impactos que a exploração dessa energia geraria na região, além do já atestado comprometimento que isso causaria na maior área úmida do planeta, o Pantanal. 
Diante do exposto até o presente momento, importante agora voltar-se para a produção atual de energia na BAP. Num levantamento inédito, tendo como um dos propósitos a consolidação deste material científico, foi construído um mapa on-line dinâmico ${ }^{3}$, com a delimitação da Bacia do Alto Rio Paraguai e o apontamento de todos os empreendimentos hidrelétricos existentes neste território. No mapa, são compreendidos, além dos empreendimentos em operação, as barragens em fase de construção, outorga e estudo (Figura 3).

Figura 3 - Mapa com a delimitação da Bacia do Alto Rio Paraguai e dos empreendimentos hidrelétricos existentes em suas diferentes fases

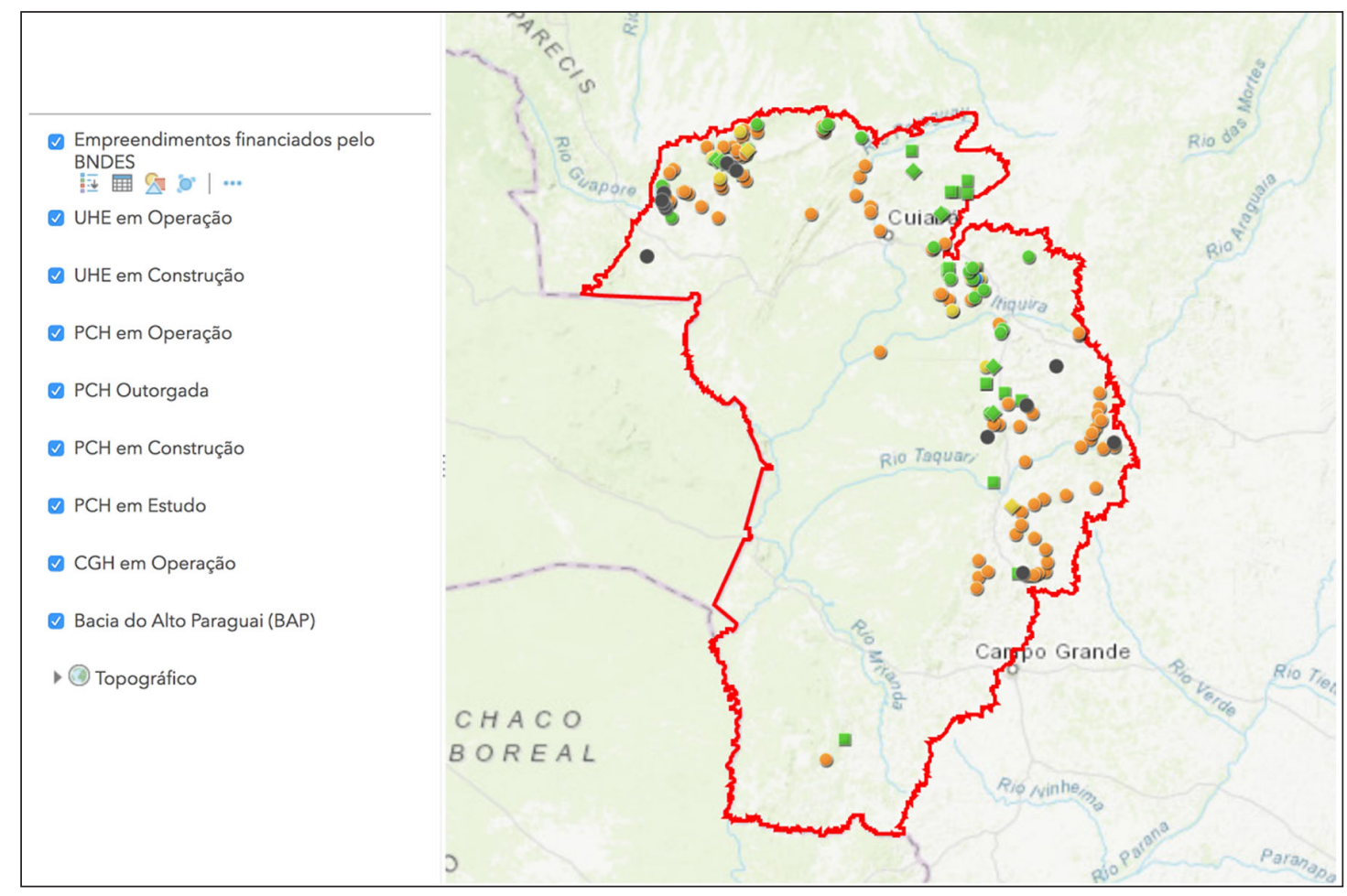

Fonte: Ecologia e Ação (ECOA, 2019).

Informações importantes foram inseridas durante a construção deste mapa, tais como a localização georreferenciada de cada empreendimento, o nome do proprietário, o rio que sofreu o barramento, o potencial de geração da usina e se o empreendimento recebeu facilidades de financiamento para o seu negócio a partir de empréstimos da maior agência de financiamento do país, o BNDES.

A partir da construção deste mapa, foi possível o acesso a números que darão o tom para uma discussão alicerçada em bases sólidas. Os primeiros que devem ser apresentados são os referentes à quantidade de empreendimentos geradores de energia hídrica no território, que somam 52 usinas em operação (Figura 4), das quais sete são denominadas de Usinas Hidrelétricas (UHEs) (usinas de grande porte, com capacidade de produzir acima de $30 \mathrm{MW}$ por hora e com

\footnotetext{
${ }^{3}$ Mapa elaborado sob a coordenação de Silvia Zanatta, sob os auspícios da Organização Não Governamental Ecoa - Ecologia e Ação. O mapa foi elaborado a partir de dados oficiais da ANEEL, do Sistema de Informação Georreferenciada do Setor Elétrico (SIGEL) e do BNDES. Imprescindível destacar que este mapa dinâmico compreende várias outras informações. Todas coletadas, organizadas e disponibilizadas a partir do trabalho de muitos outros pesquisadores e coordenadores. Assim sendo, somente o conteúdo aqui em questão - que compreende as represas na BAP - é que ficou sob a coordenação de Silvia Zanatta.
} 
áreas alagadas para reservatório acima de 13 km), 26 são Pequenas Centrais Hidrelétricas (PCHs) (usinas de pequeno porte com capacidade instalada maior do que $3 \mathrm{MW}$ e no máximo $30 \mathrm{MW}$ por hora) e 19 são Centrais Geradoras Hidrelétricas (CGHs) (usinas com potência máxima geradora de até $1 \mathrm{MW}$ por hora).

Figura 4 - Empreendimentos geradores de energia hídrica alocados na Bacia do Alto Rio Paraguai

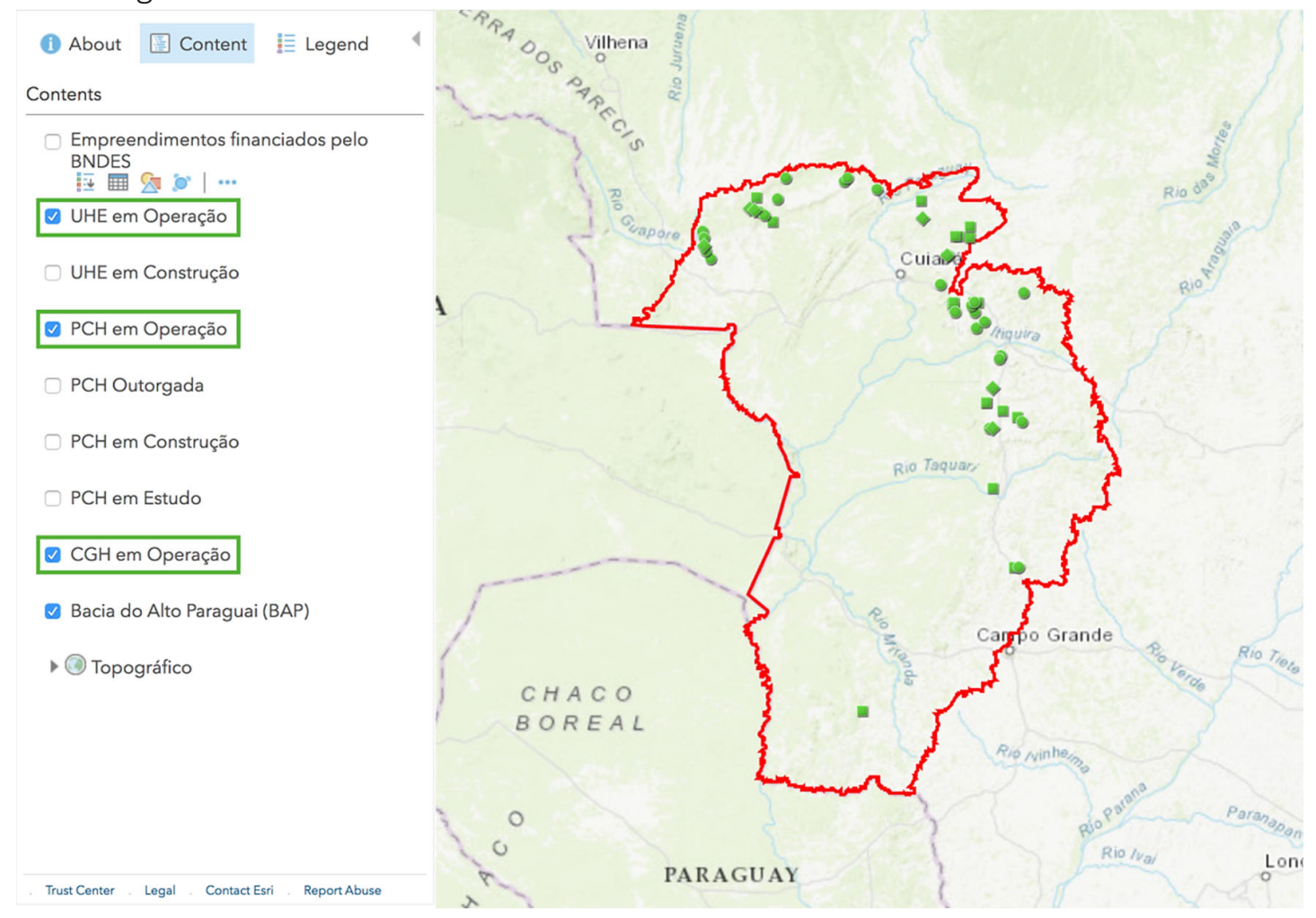

Fonte: Ecoa (2019).

Para uma Bacia tão sensível como a BAP, a existência de 52 represas é um fato alarmante. Todavia os números conseguem retratar uma realidade ainda mais preocupante quando os apontamentos recaem sobre os empreendimentos em fase de construção e em fase de estudos para serem viabilizados (Figura 5), visto que, no total, são 101 projetos. 
Figura 5 - Empreendimentos geradores de energia hídrica em fase de estudo na Bacia do Alto Rio Paraguai

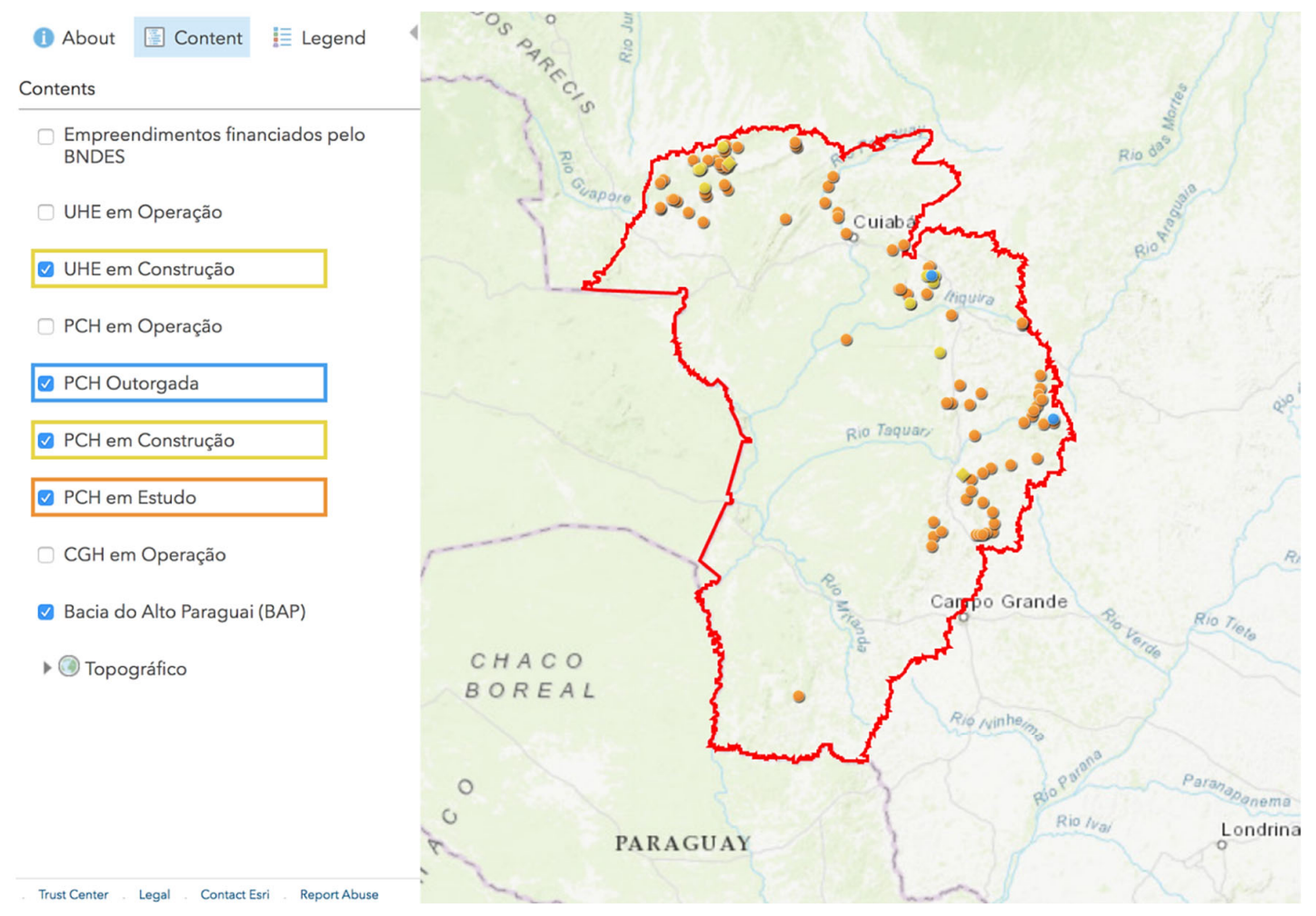

Fonte: Ecoa (2019).

Importante ressaltar ainda que a representatividade desta energia gerada na Bacia do Alto Rio Paraguai, em relação ao montante geral de energia hídrica hoje produzida no Brasil, é insignificante para justificar a construção de tantas barragens. Os dados encontrados foram apresentados na Figura 6.

Figura 6 - Representatividade da energia gerada na Bacia do Alto Rio Paraguai em relação ao montante geral de energia hídrica hoje produzida no Brasil

\begin{tabular}{|c|c|c|c|}
\hline FONTE DE GERAÇÃo & QUANTIDADE & $\begin{array}{c}\text { POTÊNCIA } \\
\text { OUTORGADA (kW) }\end{array}$ & $\%$ \\
\hline $\begin{array}{c}\text { Geração } \\
\text { Hídrica Brasil }\end{array}$ & 1.341 & 444454444 & \\
\hline $\begin{array}{c}\text { Geração } \\
\text { Hídrica BAP }\end{array}$ & 52 & 108.463 .347 & \\
\hline
\end{tabular}

Fonte: Os próprios autores. 
Logo, pode-se atestar que a produção de energia gerada na BAP se mostra irrisória diante do quadro nacional. Com 52 empreendimentos em operação - que representam 3,87\% do total de empreendimentos existentes no país - produzindo 1.192,87 kW, a BAP é responsável por apenas $\mathbf{0 , 7 0}$ da geração total de energia hídrica brasileira. Informação que nos leva a deduzir que cai por terra a narrativa construída de que o território é estratégico para esta atividade e que o Brasil depende sobremaneira desta geração "local". Quando analisados os dados por tipo de empreendimento, detectamos também as insignificâncias perante o desenho geral da produção nacional.

Quando o olhar incide sobre as UHEs, causadoras dos impactos de maior relevância quando instaladas, observamos que, das 217 unidades em operação no Brasil, sete estão na Bacia do Alto Rio Paraguai. O total de energia gerada no país a partir delas é de aproximadamente 103 mil kW; destes, menos de 0,5\% é produzido no território estudado (Figura 7).

Figura 7 - Representatividade da energia gerada a partir de UHEs na Bacia do Alto Rio Paraguai em relação ao montante geral de energia hídrica gerada a partir de UHEs no Brasil

\begin{tabular}{|c|c|c|c|}
\hline FONTE DE GERAÇÃO & QUANTIDADE & $\begin{array}{c}\text { POTÊNCIA } \\
\text { OUTORGADA }(\mathrm{kW})\end{array}$ & $\%$ \\
\hline \multirow[t]{2}{*}{ UHE Brasil } & \multirow[t]{2}{*}{217} & $\begin{array}{l}4444444444 \\
4444444444 \\
4444444444 \\
4444444444\end{array}$ & \multirow[t]{2}{*}{$60,16 \%$} \\
\hline & & 102.529 .978 & \\
\hline \multirow[t]{2}{*}{ UHE BAP } & \multirow[t]{2}{*}{07} & 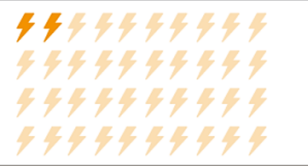 & \multirow{2}{*}{$0,47 \%$} \\
\hline & & 813.302 & \\
\hline
\end{tabular}

Fonte: Os próprios autores.

Situação nada diferente foi encontrada a partir das análises de produção via Pequenas Centrais Hidrelétricas e Centrais Geradoras Hidrelétricas. O que se tem, ainda, são dados reforçando a ideia de que os prejuízos causados à região não são válidos diante do aproveitamento hidrelétrico fixado (Figuras 8 e 9). 
Figura 8 - Representatividade da energia gerada a partir de PCHs na Bacia do Alto Rio Paraguai em relação ao montante geral de energia hídrica gerada a partir de PCHs no Brasil

\begin{tabular}{|c|c|c|c|}
\hline FONTE DE GERAÇÃO & QUANTIDADE & $\begin{array}{c}\text { POTÊNCIA } \\
\text { OUTORGADA (kW) }\end{array}$ & $\%$ \\
\hline \multirow[t]{2}{*}{ PCH Brasil } & \multirow[t]{2}{*}{425} & 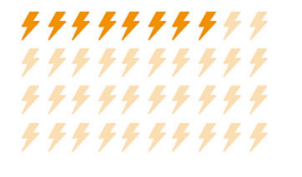 & \multirow{2}{*}{$3,16 \%$} \\
\hline & & 5.221 .329 & \\
\hline \multirow[t]{2}{*}{ PCH BAP } & \multirow[t]{2}{*}{26} & 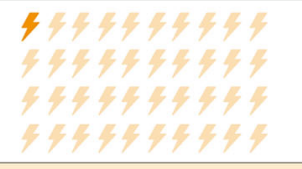 & \multirow[t]{2}{*}{$0,24 \%$} \\
\hline & & 403.381 & \\
\hline
\end{tabular}

Fonte: Os próprios autores.

Figura 9 - Representatividade da energia gerada a partir de CGHs na Bacia do Alto Rio Paraguai em relação ao montante geral de energia hídrica gerada a partir de CGHs no Brasil

\begin{tabular}{|c|c|c|c|}
\hline FONTE DE GERAÇÃO & QUANTIDADE & $\begin{array}{c}\text { POTÊNCIA } \\
\text { OUTORGADA (kW) }\end{array}$ & $\%$ \\
\hline \multirow[t]{2}{*}{$\mathrm{CGH}$ Brasil } & \multirow[t]{2}{*}{699} & 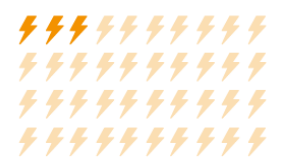 & \multirow{2}{*}{$0,53 \%$} \\
\hline & & 712.040 & \\
\hline \multirow[t]{2}{*}{ CGH BAP } & \multirow[t]{2}{*}{19} & 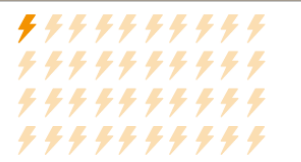 & \multirow{2}{*}{$0,01 \%$} \\
\hline & & 28.101 & \\
\hline
\end{tabular}

Fonte: Os próprios autores.

Pelo exposto, percebe-se que, dos três tipos de fonte de produção hídrica, o que ainda ganha alguma notoriedade no território, tanto em quantidade de unidades quanto em potência gerada, é a Pequena Central Hidrelétrica (PCH). Ainda que responsáveis por irrisórios 0,24\% da produção nacional, são os empreendimentos que mais oferecem ameaças para a BAP. Tal fato se deve à ideia errônea de que estes empreendimentos são fontes limpas de geração de energia, causando impactos ambientais insignificantes. Um discurso que se fortalece e que se faz valer verdadeiro quando, por exemplo, o governo e empresas privadas comparam PCHs a grandes usinas nucleares. Em função disso, o Brasil tem flexibilizado as normas ambientais e concedido incentivos financeiros com o objetivo de facilitar e agilizar a implantação de empreendimentos deste segmento em todo país. 


\section{DANOS AMBIENTAIS, SOCIAIS E ECONÔMICOS}

Um dos primeiros trabalhos publicados sobre os impactos das represas na BAP foi elaborado em 2002 pelo pesquisador Pierre Girard, professor da Universidade Federal de Mato Grosso (UFMT). Intitulado "Efeitos Cumulativos de Barragens no Pantanal", o estudo mostra alguns dos danos causados por represas em operação na região e faz projeções sobre as possíveis consequências dos efeitos cumulativos para o Pantanal, caso todas as barragens previstas àquela altura viessem a entrar em operação. Girard expõe sobre as modalidades de impactos, particularmente sobre os ecossistemas aquáticos, sua diversidade biológica e, também, sobre o ciclo natural das cheias nas planícies inundáveis. A respeito da biodiversidade e dos ecossistemas aquáticos, o autor explica que a condição da vazão de um rio, a carga e a composição dos sedimentos, a forma e o material do canal são fatores que exercem controle sobre os habitats e as espécies, o que leva a concluir que qualquer alteração neste fluxo, principalmente quando há mais do que uma barragem no mesmo rio, pode afetar a cobertura vegetal da região, causar um desequilíbrio sobre as plantas aquáticas, além de alterar significantemente o movimento lateral dos mamíferos, répteis e anfíbios que estão ligados ao regime das cheias e secas da localidade.

Outro ponto destacado por Girard (2002) é que, sendo o fluxo da água retardado, atrás das barragens, a temperatura muda, e os nutrientes e sedimentos são retidos. Se a represa for rasa, a temperatura nos rios da Bacia do Alto Rio Paraguai tenderá a subir e, consequentemente, o conteúdo de oxigênio dissolvido poderá diminuir. Em reservatórios profundos, como o da Usina de Manso, a maior da região e já em operação desde 2003, a água no fundo é muito mais fria do que a água que chega pelo fluxo normal do rio, e essa mudança de temperatura na represa afeta a temperatura rio abaixo, o que causa diminuição das espécies aquáticas. As barragens impedem a migração reprodutiva, diminuindo ou até levando à extinção algumas espécies de peixes.

A modificação do regime de fluxo causado pelas barragens leva à redução da inundação rio abaixo, tanto em relação ao espaço quanto ao tempo. Muitas espécies em planícies inundáveis, como o Pantanal, estão adaptadas às cheias anuais, sendo o principal impacto esperado com a redução dos picos de inundação a diminuição da área da planície inundável, submetida à alternância anual das fases terrestre e aquática pelo pulso das cheias. Esse ciclo mantém uma alta produtividade, abundância e diversidade nas planícies inundáveis (JUNK; BAYLEY; SPARKS, 1989).

Outra fragilidade gerada pela instalação de empreendimentos hidrelétricos na Bacia do Alto Rio Paraguai recai sobre as questões econômicas e sociais. Se levarmos em consideração que a pesca, em suas várias modalidades, é a atividade que mais gera trabalho e renda na planície pantaneira, logo podemos constatar que a economia de muitas cidades e a vida de muitos trabalhadores será afetada. Como exemplo, pode-se analisar a cidade de Corumbá, MS, maior município da região Centro-Oeste do país, com aproximadamente 108 mil habitantes. Destes, 30 mil são pessoas que dependem direta e indiretamente da atividade pesqueira. Em sua maioria, são piloteiros e trabalhadores em barcos de turismo pesqueiro, pescadores artesanais, ribeirinhos e coletores de iscas vivas. Só no ano de $2015^{4}$, segundo a Associação Corumbaense das Empresas Regionais de Turismo (ACERT), o município de Corumbá recebeu mais de 52 mil turistas, que movimentaram 101 milhões de reais na região. Dados que revelam a importância das modalidades da pesca no município.

\footnotetext{
${ }^{4}$ Importante deixar registrado que, depois destes dados, divulgados em 2015, não houve a publicação por parte da ACERT de dados atualizados. Existe a previsão de que, até o final de 2020, novos indicativos sejam disponibilizados.
} 
A pesca turística é tida como a mais dinâmica economicamente. A partir de seus barcoshotéis e barcos-pousadas, estrutura toda uma cadeia geradora de empregos diretos e indiretos em agências de turismo; companhias aéreas; hotéis e bares; e nos vários estaleiros e oficinas existentes em algumas cidades pantaneiras. Importante ressaltar também que a pesca turística tem acoplada a ela a modalidade específica de atividade extrativista identificada como captura de iscas vivas, que é praticada por ribeirinhos e comunidades tradicionais. Álvaro Banducci, pesquisador da Universidade Federal de Mato Grosso do Sul (UFMS), em trabalho intitulado "Turismo Cultural e Patrimônio", publicado em 2003, demonstra que a atividade é realizada por toda a extensão do Rio Paraguai, a partir da foz do Rio São Lourenço (divisa entre MS e MT) até ao Sul do Pantanal, em Porto Murtinho. Nesta última região, os Ayoreos, indígenas que vivem em território paraguaio, são os que praticam a captura.

Estes grupos, chamados regionalmente de "isqueiros", são considerados os mais vulneráveis, e isso ocorre sob vários aspectos. Imagine, somada a estas vulnerabilidades já inerentes, a construção de mais 101 empreendimentos causando a barragem dos rios que os mantêm.

\subsection{A sociedade civil, pesquisadores e o Ministério Público apontam o caminho: Avaliação Ambiental Estratégica (AAE)}

A AAE é destinada a identificar como compatibilizar as políticas, os planos e programas, bem como a sustentabilidade dos usos e da conservação dos bens naturais de um território. Por essas razões, várias instituições e organizações da sociedade civil, entre elas, a Coalizão Rios Vivos, a Rede Pantanal, a Embrapa Pantanal e a Ecoa (Ecologia e Ação), desenvolveram campanha desde a primeira década deste século, para que essa ferramenta fosse adotada para a BAP e a produção de energia elétrica a partir de represas. O entendimento era o de que os efeitos cumulativos de vários empreendimentos previstos, incluindo Pequenas Centrais Hidrelétricas (PCHs), deveriam ser avaliados em seu conjunto para se ter um diagnóstico dos efeitos cumulativos e, assim, estabelecer o que se poderia e o que não se deveria construir.

Em cinco de março de 2009, por meio da Portaria n. 004/2009, o Dr. Wilson Rocha Assis, procurador da República no município de Corumbá, MS, instaurou um procedimento para analisar as influências das barragens, usinas e centrais hidrelétricas no funcionamento "hidroecológico do Pantanal". Tomou por base recomendações do workshop "Influências das Barragens para Geração de Energia Hidroelétrica sobre o Funcionamento Hidroecológico do Pantanal MatoGrossense", realizado durante a Conferência Internacional de Áreas Úmidas, evento organizado pela UFMT, em julho de 2008.

Posteriormente, em 2012, o Ministério Público Federal ajuizou uma ação civil pública na 1 a Vara Federal de Coxim (MS), na qual apresentava a exigência de que a União, os estados de Mato Grosso do Sul e de Mato Grosso, a ANEEL, a Empresa de Pesquisa Energética (EPE), o Instituto Brasileiro do Meio Ambiente e dos Recursos Naturais Renováveis (IBAMA) e o Instituto do Meio Ambiente de Mato Grosso do Sul (IMASUL) suspendessem quaisquer licenciamentos de represas na BAP antes da realização de uma AAE. A ação foi vitoriosa na primeira instância da Justiça Federal, mas posteriormente derrotada em instâncias superiores.

De qualquer maneira, as iniciativas propondo a realização da Avaliação Ambiental Estratégica estabeleceram um novo marco para os debates sobre as represas na Bacia e, provavelmente, seja o fio condutor que levou a Agência Nacional de Águas (ANA) a contratar o "Estudo de Avaliação 
dos Efeitos da Implantação de Empreendimentos Hidrelétricos na Região Hidrográfica do Rio Paraguai", a ser concluído em maio de 2020, e determinar, em setembro de 2018, a suspensão temporária da emissão de autorizações para implantar novas hidrelétricas na Bacia Hidrográfica do Paraguai até que o estudo citado acima seja concluído.

\section{CONCLUSÕES}

Historicamente, a narrativa envolvendo a proliferação de represas pelo Brasil é calcada no discurso do desenvolvimento e, de modo mais recente, nos discursos da energia renovável, limpa e de custo baixo. Fato que nos dá base para defender que existe uma constituição de desastres ambientais esquematizados, planejados e regularizados pelo poder público e privado, que causam intensos estragos socioambientais e irreparáveis danos nos modos de vida e no trabalho das populações impactadas. E o resultado de projetos de desenvolvimento impositivos que visam, única e exclusivamente, atender o modelo capitalista não pode ser outro além da miséria se instalando no lar de pessoas que vivem e tiram seu sustento dos rios.

Ao fim da construção deste artigo, é possível atestar que as narrativas construídas em defesa da exploração dos recursos hídricos da Bacia do Alto Rio Paraguai para geração de energia são frágeis e injustificáveis. O impacto gerado no território é inenarrável diante da insignificância de energia gerada. Mais uma vez, destaca-se: a produção na BAP representa ínfimos 0,70\% de toda produção energética hídrica do país.

Foi possível também detectar que vem sendo empregada, neste território, a máxima de Descartes (1978), bastante conhecida, de que o homem se faz "mestre e senhor da natureza", em que a natureza composta, a partir de então, de objetos sem ligação com humanos, como as plantas, animais, terras, água e rochas, é convertida em meros recursos que podemos usar e dos quais podemos tirar proveito. Realidade instalada pela falta de sensibilidade hoje imperante de um olhar sistêmico e amplo. E o que se perde com este olhar fragmentado e fraturado é a oportunidade de nos habituarmos a representar a natureza como um todo, tornando-a, por assim dizer, um grande relógio, do qual podemos desmontar os mecanismos e cujas peças e engrenagens podemos aperfeiçoar (DESCOLA, 2016).

Por fim, percebe-se também que, para enfrentar os problemas já estabelecidos e oriundos da instalação dos empreendimentos hidroelétricos na BAP, é necessária a adoção de estratégias e políticas públicas para a minimização dos impactos que o território sofre. Importante destacar que qualquer iniciativa para mitigar estes impactos deva convergir, necessariamente, com a perspectiva de romper com valores baseados na lógica antropocêntrica e assumir uma mudança de paradigma, adotando uma postura voltada para valores que se aproximem de uma lógica centrada nos direitos da Terra e no respeito pelos povos que mantêm uma estreita relação com seu território.

\section{REFERÊNCIAS}

AGÊNCIA NACIONAL DE ÁGUAS [ANA]. Bacias brasileiras do rio da Prata: avaliações e propostas. Brasília: ANA, 2001.

ALBUQUERQUE, Ralph de Medeiros. As pequenas centrais hidrelétricas da bacia do rio Iratim e seus impactos socioambientais: uma reflexão sobre eletroestratégias e acumulação por espoliação. 2013. Monografia (Graduação em Geografia) - Universidade Federal do Paraná, Curitiba, PR, 2013. 
ALMEIDA, Alfredo Wagner Berno. Agroestratégias e desterritorialização: direitos territoriais e étnicos na mira dos estrategistas do agronegócio. In: ALMEIDA, Alfredo Wagner Berno. Capitalismo globalizado e recursos territoriais: fronteiras da acumulação no Brasil contemporâneo. Rio de Janeiro: Lamparina, 2010. p. 101-44.

AGÊNCIA NACIONAL DE ÁGUAS [ANEEL]. Sistema de Informação de Geração da ANEEL - SIGA. ANEEL, Brasília, 2019. Página inicial. Disponível em: https://app.powerbi.com/view? r=eyJrljoiNjc4 OGYyYjQtYWM2ZC00YjIILWJIYmEtYZdkNTQ1MTc1NjM2liwidCI6IjQwZDZmOWI4LWVjYTctNDZhMi05M mQ0LWVhNGU5YZAxNzBIMSIsImMiOjR9. Acesso em: 21 mar. 2020.

BANDUCCI JR., Álvaro. Turismo cultural e patrimônio: a memória pantaneira no curso do rio Paraguai. Horizontes Antropológicos, Porto Alegre, v. 9, n. 20, p. 117-40, 2003.

BERMANN, Célio; VEIGA, José Roberto Campos; ROCHA, Georges Souto. A repotenciação de usinas hidrelétricas como alternativa para o aumento da oferta de energia no brasil com proteção ambiental. Brasília-DF: WWF, 2004. Disponível em: https://wwfeu.awsassets.panda.org/downloads/ repotenciacaouheportugues.pdf. Acesso em: 18 ago. 2021.

BRASIL. Ministério do Meio Ambiente dos Recursos Hídricos e da Amazonia Legal. Plano de conservação da Bacia do Alto Paraguai (Pantanal). 1. ed. Brasília-DF: PNMA, 1997.

DESCARTES, René. O discurso do método. São Paulo: Hemus, 1978. Disponível em: http://public. ebookcentral.proquest.com/choice/publicfullrecord.aspx?p=3157240. Acesso em: 21 mar. 2020.

DESCOLA, Philippe. Outras naturezas, outras culturas. 1. ed. São Paulo: Editora 34, 2016.

ECOLOGIA E AÇÃO [ECOA]. Represas na Bacia do Alto Paraguai (BAP). ArcGIS, [s.I.], 2019. Disponível em https://www.arcgis.com/home/webmap/viewer.html?webmap=ef58538671604b838a9ed5e976b4e82f \&extent=-65.0959,-23.684,-43.5627,-13.2819. Acesso em: 20 mar. 2020.

GIRARD, Pierre. Efeito cumulativo das barragens no Pantanal: mobilização para conservação das áreas úmidas do Pantanal e Bacia do Araguaia. Campo Grande: Instituto Centro Vida, 2002.

JUNK, Wolfgang Johannes; BAYLEY, Peter; SPARKS, Richard. The flood pulse concept in river-floodplain systems. In: DODGE, Douglas P. (Org.). Proceedings of the International Large River Symposium (LARS). Ottawa: Department of Fisheries and Oceans, 1989. p. 110-27.

SILVA, Tereza Cardoso. Contribuição da geomorfologia para o conhecimento e valorização do Pantanal. In: SIMPÓSIO SOBRE OS RECURSOS NATURAIS E SOCIOECONÔMICOS DO PANTANAL, 1., UFMS, Corumbá, 1984. Anais [...]. Brasília: EMBRAPA/DDT/CPAP, 1986. p. 77-90.

THE NATURE CONSERVANCY; WWF-BRASIL. Análise de Risco Ecológico da Bacia do Rio Paraguai: Argentina, Bolívia, Brasil e Paraguai. Brasília-DF: The Nature Conservancy do Brasil, 2011.

\section{Sobre os autores:}

Silvia Cristina Santana Zanatta: Doutorado e mestrado em Desenvolvimento Local pela Universidade Católica Dom Bosco (UCDB). Especialização em Comunicação: Linguagem, Construção Textual e Literatura pela Libera Limes. Graduação em Jornalismo pela Universidade para o Desenvolvimento do Estado e da Região do Pantanal (UNIDERP). Pesquisadora na região da Bacia do Rio da Prata ligadas a monitoramento de agências financiadoras do desenvolvimento, conservação ambiental, gestão territorial e comunidades tradicionais. E-mail: silviasantana1@gmail.com, 
Orcid: http://orcid.org/0000-0001-7227-4519

Josemar de Campos Maciel: Estágio pós-doutoral em Estudos Culturais pela Universidade de São Paulo (USP). Doutorado em Psicologia pela Pontifícia Universidade Católica de Campinas (PUC-Campinas). Mestrado em Psicologia pela Universidade Católica Dom Bosco (UCDB) e em Teologia Sistemática pela Pontifícia Universidade Gregoriana de Roma (PUG). Graduação em Filosofia pelas Faculdades Unidas Católicas de Mato Grosso (FUCMT) e em Teologia pela PUG. Professor de mestrado em Desenvolvimento Local na UCDB. E-mail: maciel50334@yahoo.com.br, Orcid: http://orcid.org/0000-0001-8277-9422 